\title{
The value of salvage surgery after stereotactic body radiotherapy failure: A sticky conundrum
}

\author{
Benjamin Wei, MD
}

\footnotetext{
From the Division of Cardiothoracic Surgery, Department of Surgery, University of Alabama Birmingham School of Medicine, Birmingham, Ala.

Disclosures: Author has nothing to disclose with regard to commercial support.

Received for publication April 9, 2017; accepted for publication April 12, 2017; available ahead of print May 10, 2017.

Address for reprints: Benjamin Wei, MD, Division of Cardiothoracic Surgery, Department of Surgery, University of Alabama Birmingham School of Medicine, ZRB 739, 1720 2nd Ave S, Birmingham, AL 35294-0007 (E-mail: bwei@uabmc.edu).

J Thorac Cardiovasc Surg 2017;154:700-1

0022-5223/\$0.00

Published by Elsevier Inc. on behalf of The American Association for Thoracic Surgery http://dx.doi.org/10.1016/j.jtcvs.2017.04.020
}

In their study published in this month's Journal, Antonoff and colleagues $^{1}$ at the MD Anderson Cancer Center provide a compelling early look at some patients whom thoracic surgeons will certainly encounter more in the future: namely, patients who have undergone previous stereotactic body radiotherapy (SBRT) for lung cancer or other malignancies metastatic to the lung and subsequently have a local recurrence. SBRT is an increasingly used modality in the United States and worldwide, with applications even in cases where histologic or cytologic diagnosis is not achieved (as many as $40 \%$ in some recent cohorts ${ }^{2}$ ). Whereas SBRT in the past was typically considered primarily for patients considered medically unfit for or at high risk from surgery, the modality is now being used for some patients who could undergo pulmonary lobectomy safely. ${ }^{3}$ As the use of SBRT increases, so will the number of patients seen with a local recurrence. Antonoff and colleagues ${ }^{1}$ have shown that salvage resection in selected patients with this presentation is a reasonable option from a perioperative risk standpoint. Their study size was small; it included 21 of their own patients and synthesized data from 3 other studies, for a total of 37 patients in the analysis. Although Antonoff and colleagues ${ }^{1}$ are to be commended for benchmarking their experience to results derived from the Society of Thoracic Surgeons database and other large video-assisted thoracoscopic surgery series, it is not necessarily fair to compare these patients. More than $90 \%$ of their patients underwent thoracotomy; furthermore, their patients were older, had more comorbidities, and had a lower median forced expiratory volume in 1 second and diffusing capacity of the lungs for carbon monoxide than those in contemporary series on surgical therapy for lung cancer. ${ }^{4}$ The message seems to be that salvage resection can be done safely, despite a significant risk of adhesions, which were described as "severe" or "extensive" in nearly $50 \%$ of cases. It is possible that with greater experience more of these cases could potentially be performed with minimally invasive techniques, such as video-assisted thoracoscopic surgery and robotic surgery, which would be expected to lead to fewer surgery!

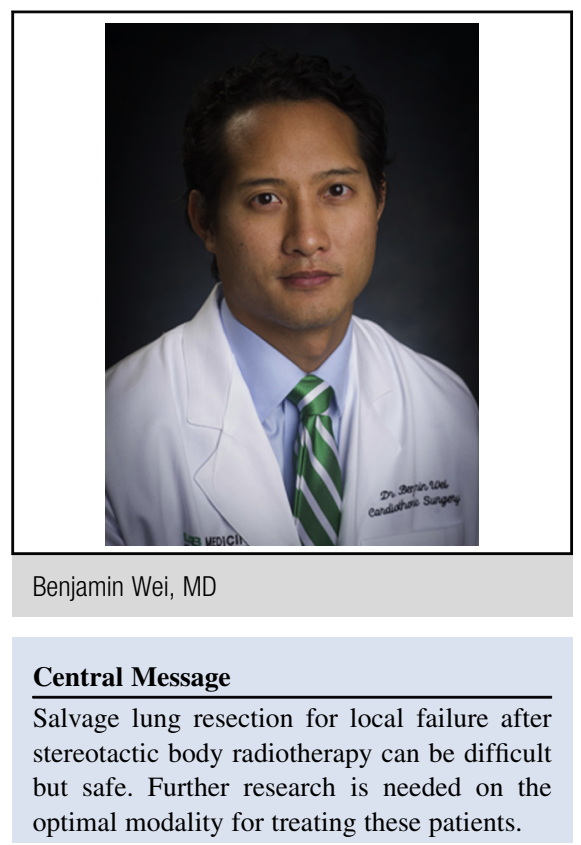

See Article page 689

complications. The larger question, however, is whether salvage resection is the right decision from an oncologic standpoint. Here, the study shows a disparity in results between patients with lung cancer and patients with other malignancies. The median survival after surgery was only 13.6 months for patients with lung cancer at the MD Anderson Cancer Center (3-year survival of $43.1 \%$ ), whereas the end point for median survival was not reached in the metastatic disease group (3-year survival of $87.5 \%$ in the cumulative group). The natural history of patients with a local recurrence after SBRT has not been well studied, nor is this group even easily defined. These facts, combined with of the sobering survival data of the lung cancer group, lead to the next logical question: Should these patients be treated instead with a less invasive modality than surgery, with advantages in terms of morbidity and recovery time? Patients with a local recurrence after SBRT may not be candidates for further radiation, but therapies such as cryoablation and microwave ablation could be viable alternatives. ${ }^{5,6}$ It will be difficult to compare surgery with these modalities, because selection bias will come into play in the absence of a randomized trial; if the latter is contemplated, however, perhaps patient accrual will be less difficult than it has been for trials comparing SBRT and 


\section{References}

1. Antonoff MB, Correa AM, Sepesi B, Nguyen QN, Walsh GL, Swisher SG, et al. Salvage pulmonary resection following stereotactic body radiotherapy: a feasible and safe option for local failure in selected patients. J Thorac Cardiovasc Surg. 2017; 154:689-99.

2. Peguret N, Dahele M, Lagerwaard F, Senan S, Slotman BJ. A brief report of 10year trends in the use of stereotactic lung radiotherapy at a Dutch academic medical center. J Thorac Oncol. 2014;9:114-7.

3. Rosen JE, Salazar MC, Wang Z, Yu JB, Decker RH, Kim AW, et al. Lobectomy versus stereotactic body radiotherapy in healthy patients with stage I lung cancer. J Thorac Cardiovasc Surg. 2016;152:44-54.e9.

4. Onaitis MW, Petersen RP, Balderson SS, Toloza E, Burfeind WR Harpole DH Jr, et al. Thoracoscopic lobectomy is a safe and versatile procedure: experience with 500 consecutive patients. Ann Surg. 2006;244: 420-5.

5. Kim C, Hoang CD, Kesarwala AH, Schrump DS, Guha U, Rajan A. Role of local ablative therapy in patients with oligometastatic and oligoprogressive non-small cell lung cancer. J Thorac Oncol. 2017; 12:179-93.

6. Smith SL, Jennings PE. Lung radiofrequency and microwave ablation: a review of indications, techniques and post-procedural imaging appearances. $\mathrm{Br} J$ Radiol. 2015;88:20140598. 